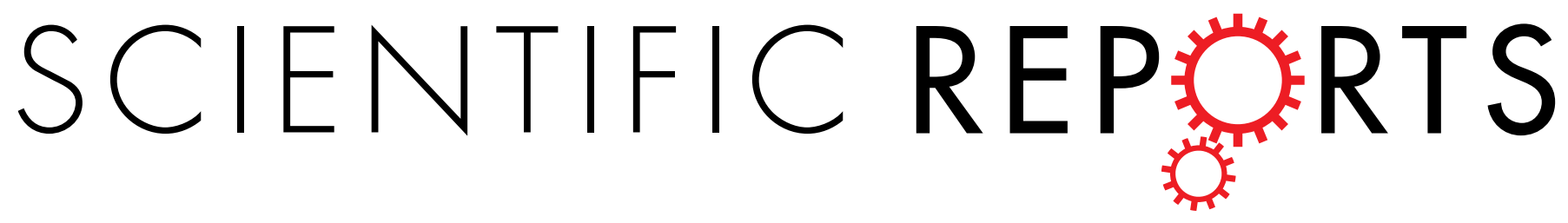

Received: 29 June 2018

Accepted: 10 May 2019

Published online: 23 May 2019

\section{Ras suppressor-1 (RSU-1) promotes cell invasion in aggressive glioma cells and inhibits it in non- aggressive cells through STAT6
phospho-regulation}

Maria Louca ${ }^{1}$, Andreas Stylianou ${ }^{1}$, Angeliki Minia ${ }^{2}$, Vaia Pliaka ${ }^{2}$, Leonidas G. Alexopoulos ${ }^{2,3}$, Vasiliki Gkretsi ${ }^{4}{ }^{4}$ Triantafyllos Stylianopoulos ${ }^{1}$

Most gliomas are invasive tumors formed from glial cells and associated with high mortality rates. In this study, we characterized four glioma cell lines of varying degree of aggressiveness (H4, SW1088, A172 and U87-MG) in terms of morphology, cytoskeleton organization and stiffness, and evaluated their invasive potential by performing invasion, colony forming and spheroid invasion assays. Cells were divided into two distinct groups: aggressive cell lines (A172 and U87-MG) with more elongated, softer and highly invasive cells and less aggressive cells (H4 and SW088). Interestingly, we found that Ras Suppressor-1 (RSU-1), a cell-matrix adhesion protein involved in cancer cell invasion, was significantly upregulated in more aggressive glioma cells compared to less aggressive. Importantly, RSU-1 silencing had opposing effects on glioma cell invasion depending on their aggressiveness, inhibiting migration and invasion of aggressive cells and promoting those of less aggressive cells. Finally, we found that RSU1 silencing in aggressive cells led to decreased Signal Transducer and Activator of Transcription6 (STAT6) phosphorylation and Matrix Metalloproteinase13 (MMP13) expression in contrast to less invasive cells. Our study demonstrates that $R S U-1$ promotes invasion of aggressive glioma cells and inhibits it in the non-aggressive cells, indicating that it could serve as a predictor of gliomas progression.

Gliomas are characterized by rapid progression and high mortality rates. Glioblastoma multiforme (GBM), a type of astrocytoma arising from uncontrolled proliferation of astrocytes, is the most aggressive type of malignant brain tumors in the cerebral hemispheres ${ }^{1,2}$. Its treatment, as with all gliomas, is multimodal consisting of surgical removal, radiotherapy and chemotherapy. However, although there are several therapeutic modalities, GBM still has poor prognosis due to the increased incidence of invasion of cancer cells into adjacent tissue forming metastases $^{3-5}$. Indeed, invasion and migration of glioma cells away from the main tumor mass, is one of the most important issues in glioma therapy, being highly associated with decreased survival rates ${ }^{6}$. Genetic instability and deregulation of multiple focal adhesion (FA) proteins are known to be crucially involved in these processes ${ }^{7,8}$. FA proteins are localized at cell-extracellular matrix (ECM) sites transducing biochemical and biomechanical cues from the ECM and integrins to effector molecules inside the cell, while most of them are directly interacting with actin cytoskeleton and are involved in many cellular processes such as survival, differentiation, proliferation, migration and invasion ${ }^{9,10}$.

Ras Suppressor-1 (RSU-1) was first identified as a suppressor of Ras oncogene ${ }^{11}$, exhibiting growth suppression effects ${ }^{12-16}$ while it was later found to be localized to cell-ECM adhesion sites through its interaction with Particularly Interesting New Cysteine-Histidine rich protein (PINCH-1) ${ }^{17}$. Beyond cancer cell proliferation, RSU-1 has been also documented to play a crucial role in cancer cell migration and invasion ${ }^{18-22}$ both of which

${ }^{1}$ Cancer Biophysics Laboratory, Department of Mechanical and Manufacturing Engineering, University of Cyprus, Nicosia, Cyprus. ${ }^{2}$ ProtATonce Ltd., Athens, Greece. ${ }^{3}$ Department of Mechanical Engineering, National Technical University of Athens, Athens, Greece. ${ }^{4}$ Biomedical Sciences Program, Department of Life Sciences, School of Sciences, European University Cyprus, Nicosia, Cyprus. Correspondence and requests for materials should be addressed to V.G. (email: vasso.gkretsi@gmail.com) orT.S. (email: tstylian@ucy.ac.cy) 
are fundamental steps in the metastatic process. Little is known, however, regarding $R S U-1$ expression and its role in tumors of the central nervous system ${ }^{23}$. It is hypothesized though that it should be involved in glioma pathogenesis as well, as it seems to play a critical role in regulating synapse maturation by preventing spontaneous clustering of extrasynaptic acetylocholine receptors ${ }^{24}$ and enhances Nerve Growth Factor (NGF)-induced neuronal differentiation ${ }^{25}$. Also, lack of $R S U-1$ activates c-Jun N-terminal protein kinase (JNK) and neural stem and progenitor cell (NSPC) proliferation ${ }^{26}$. Hence, the main objective of this research work was the in vitro characterization of a panel of four commercially available glioma cell lines of varying degrees of invasiveness, namely H4, SW1088, A172 and U87-MG in terms of morphology, cytoskeleton organization, stiffness and aggressiveness as well as the determination of the involvement of RSU-1 in the metastatic properties of glioma cells.

\section{Materials and Methods}

Glioma cell lines. A panel of human glioma cell lines (H4, SW1088, A172 and U87-MG) was purchased from ATCC. H4 cells are non-tumorigenic epithelial brain cells, SW1088 are responsible for astrocytoma formation, whereas U87-MG and A172 were isolated from patients with GBM. Cells were grown in high-glucose DMEM medium supplemented with $10 \%$ fetal bovine serum and $1 \%$ antibiotic/antimycotic and were cultured in a humidified incubator supplied with $5 \% \mathrm{CO} 2$ at $37^{\circ} \mathrm{C}$.

Antibodies and reagents. Anti-RSU-1 rabbit polyclonal antibody for immunoblotting was kindly provided by Dr. Mary Lou Cutler, Professor at the Uniformed Services University of the Health Sciences, Bethesda USA. Anti-pSTAT6 and anti-STAT6 were obtained from Cell Signaling. Anti-MMP13 was purchased from Abcam. Phospho-STAT6 inhibitor, AS1517499, was obtained from Axon Medchem. RSU-1 siRNA was purchased from Santa Cruz Biotechnology. Rhodamine-Phalloidin was obtained from Biotium and 4',6-Diamidino2-Phenylindole (DAPI) was obtained from Roche. Transwell inserts were purchased from Greiner Bio-One and Matrigel as well as Collagen I was obtained from Corning. QIAzol Lysis Reagent was purchased from QIAGEN.

Cell Elongation and Factor E measurement. Pictures of individual live cells were taken using a Nikon Eclipse TS100 inverted microscope equipped with a digital camera and a Nikon Ph1 DL 10x 0.25 phase microscope objective lens. ImageJ software was used to measure the factor $\mathrm{E}$ of the cells, which is calculated by dividing the longest axis by the shortest axis and subtracting one $e^{27}$. The elongation factor E describes the extent to which the equimomental ellipse is lengthened or stretched out ${ }^{28}$. Given the fact that factor $\mathrm{E}$ is zero (0) for a circle, and one (1) for an ellipsoid with an axis ratio 1:2, E values between $0-0.5$ are considered to correspond to spherical cells, $0.5-1$ to ellipsoids, and E values higher than 1 are considered to correspond to elongated cells ${ }^{29}$.

Atomic Force Microscopy (AFM). Cells were cultured in $35 \mathrm{~mm}$ petri dishes overnight. Then the samples were directly mounded on AFM sample plates. The Young's modulus of cells was acquired by using a Molecular Imaging-Agilent PicoPlus AFM system with silicon nitride probes and a round, ball-shape tip (CP-PNPL-BSG-A-5, sQube, $5 \mu \mathrm{m}$ diameter spheres, spring constant of $0.08 \mathrm{~N} / \mathrm{m}$ ). The Young's modulus which is in essence the stiffness of live cells was assessed by acquiring $8 \times 8$ points of force curves in an area of $5 \times 5 \mu \mathrm{m}$ near the center of the cells ${ }^{20}$. For the acquisition of the force-displacement curves a set point of $1 \mathrm{nN}$ normal force at a $2 \mu \mathrm{m} / \mathrm{s}$ strain rate on each of the studied cells was used ${ }^{30}$. Subsequently, the Atomicj software ${ }^{31}$ and the Hertz model were employed for the calculation of the Young's modulus, while for the calculations the Poisson's ratio was assumed to be equal to 0.5 .

Cytoskeleton assay staining and morphology identification. H4, SW1088, A172 and U87 cells were plated at a density of 10,000 cells per well on glass coverslips coated with $0.1 \%$ gelatin. Twenty-four (24) hours later, cells were fixed with $4 \%$ PFA for $20 \mathrm{~min}$ and they were then permeabilized using a buffer containing $0.1 \%$ Triton X-100 and $2 \mathrm{mg} / \mathrm{ml}$ BSA in PBS. Cells were finally double stained with Rhodamine phalloidin and DAPI ${ }^{32-}$ ${ }^{34}$. In order to characterize the actin cytoskeleton in terms of stress fiber formation and orientation, the freeware tool FilamentSensor was used. This tool is an open source software written in Java [http://filament-sensor.de/], for semi-automated detection of line segments in images. It is primarily designed for detection of actin fibers from microscopy images and it is based on the filament sensor (FS), a fast and robust processing sequence which detects and records location, orientation, length, and width for each single filament of an image ${ }^{32}$. In the analyzed figures the different fiber orientations of the F-actin stress fibers were represented with a different color $^{30,32}$.

Transwell migration and invasion assays. Cell migration and invasion assays were performed using transwell chambers with $8 \mu \mathrm{m}$ pore size membranes. The membranes of the inserts were either left uncoated and used for migration or were coated with diluted Matrigel (1:20) $24 \mathrm{~h}$ before cell seeding and used for invasion ${ }^{35,36}$. In total, $3.5 \times 10^{4}$ cells in $0.5 \mathrm{ml}$ of serum-free medium were added to the upper chamber, while the lower chamber was filled with $750 \mu \mathrm{l}$ of culture medium supplemented with $10 \%$ fetal bovine serum and $1 \%$ antibiotic/antimycotic. After a $24 \mathrm{~h}$ incubation, the non-invading cells were removed from the upper surface of the membrane using a cotton swab. The cells that had passed through the membrane were fixed with 4\% PFA for 20 min, and stained with $0.1 \%$ crystal violet in PBS for $20 \mathrm{~min}^{37-39}$. For quantification, cells in nine selected microscopic fields per well were counted, and the sum was calculated. Three independent experiments were performed.

Tumor spheroids formation in collagen gels. The "hanging drop" technique was used to generate tumor spheroids, as described previously ${ }^{20}$. A suspension of $2.5 \times 10^{4}$ glioma cells (H4, SW1088, A172 and U87-MG) was prepared and several drops of $20 \mu \mathrm{l}$ each containing 500 cells were placed on the cover of a culture dish. Spheroids were allowed to grow for 24 hours $^{40-42}$. Individual spheroids were then embedded in wells of a 96 -well plate containing $1.0 \mathrm{mg} / \mathrm{ml}$ collagen $\mathrm{I}^{20}$. Pictures were taken at time zero and at several time points. Spheroid's 


\begin{tabular}{|l|l|}
\hline Primer name & Sequence \\
\hline \multirow{2}{*}{ RSU-1 } & Forward 5' AGGCCACAGAGCAAGGTCTA 3' \\
\cline { 2 - 2 } & Reverse 5' CGT GCA ATC TCA AAA GCT CA 3' \\
\hline \multirow{2}{*}{ MMP13 } & Forward 5' TGGCATTGCTGACATCATGA3' \\
\cline { 2 - 2 } & Reverse 5' GCCAGAGGGCCCATCAA3 ${ }^{\prime}$ \\
\hline \multirow{2}{*}{$\beta$-actin } & Forward 5' CGAGCACAGAGCCTCGCCTTTGCC-3' \\
\cline { 2 - 2 } & Reverse 5' TGTCGACGACGAGCGCGGCGATAT-3' \\
\hline
\end{tabular}

Table 1. Primer sequences used for RT-PCR.

size was determined using the ImageJ software, and taking the mean length of the major and minor axis of the spheroid at a given time point compared to the initial size at time zero.

Phospho-STAT6 inhibitor treatment. Cells were treated with 100, 200 or $300 \mathrm{nM}$ of phospho-STAT6 inhibitor, AS1517499, for at least $48 \mathrm{~h}$ in high-glucose DMEM medium supplemented with $10 \%$ fetal bovine serum and $1 \%$ antibiotic/antimycotic according to previous studies ${ }^{43,44}$. Inhibition of STAT- 6 phosphorylation was verified by immunoblotting following standard procedures.

Transfection with siRNA. All cells were transfected with $100 \mathrm{nM}$ siRNA against RSU-1 or a non-specific control siRNA, using the HiPerfect reagent (Qiagen) according to the manufacturer's guidelines. Cells were harvested $48 \mathrm{~h}$ post-transfection.

Soft agar growth assay. Cells were trypsinized, suspended at a concentration of approximately $5 \times 10^{3}$ cells $/ \mathrm{ml}$ in $0.3 \%$ soft agar and placed on a layer of $0.6 \%$ soft agar in a six-well plate. After a 30 day incubation in a humidified atmosphere in the presence of $5 \% \mathrm{CO}_{2}$ at $37^{\circ} \mathrm{C}$, colonies were formed and were subsequently fixed with $4 \%$ PFA and stained with $0.01 \%$ crystal violet in PBS for $1 \mathrm{~h}^{45,46}$. Colonies were examined using an inverted microscope. Five randomly selected microscopic fields per well were used for quantification, and the number of total colonies per well were counted. Also, ImageJ software was used to measure the size of the colonies (area). The experiment was performed in triplicate for each cell line.

Sample preparation and phosphoproteins' measurements. A custom 21-plex assay was built aiming to investigate cell invasion through the regulation of influential phosphoproteins. The Multiplex assay was designed following literature search to detect the most influential phosphoproteins and discover if these signaling molecules play an important role in glioma cell invasion upon RSU-1 silencing. Cells were lysed using cell lysis buffer (LysisPlex, ProtATonce, Cat Nr: LPA01) $48 \mathrm{~h}$ post-transfection with appropriate siRNA (NSC or RSU-1 siRNA) and protein concentration was adjusted to $200 \mu \mathrm{g} / \mathrm{ml}$ with lysis buffer. Cell lysates were used for the phosphoprotein measurements. Twenty-one (21) capture antibodies coupled to Luminex magnetic beads and 21 biotinylated detection antibodies were multiplexed to create the bead mix and the detection mix, respectively. The coupled beads $(50 \mu$ l of the bead mix) were incubated with the samples on a flat bottom 96-well plate on a shaker at $900 \mathrm{rpm}$ for 90 minutes at room temperature. Then, detection mix was added, and the samples were incubated further on a shaker at $900 \mathrm{rpm}$ for 60 minutes at room tempserature. The final step was the addition of freshly prepared SAPE solution (Streptavidin, R-Phycoerythrin conjugate, Cat Nr: S866, Invitrogen) for the detection of the signal. Following a 15 minute incubation time with SAPE, samples were measured with the Luminex FlexMAP 3D instrument.

The following phospho-proteins were assessed: Transcription factor p65 (NF-Kb/TF-65, Cat Nr: P-NFKB-A01), Mitogen-activated protein kinase 12 (p38, Cat Nr: P-MK12-A01), RAC-alpha serine/ threonine-protein kinase (AKT1, Cat Nr: P-AKT1-01), Serine/threonine-protein kinase WNK1 (WNK1, Cat Nr: P-WNK1-A01), Tyrosine-protein phosphatase non-receptor type 11 (PTN11, Cat Nr: P-PTN11-A01), Signal transducer and activator of transcription 3 (STAT3, Cat Nr: P-STAT3-A01), Heat shock protein beta-1 (HSP27/HSPB1, Cat Nr: P-HSPB1-A01), Transcription factor AP-1 (JUN, Cat Nr: P-JUN-A01), Signal transducer and activator of transcription 5 A (STAT5, Cat Nr: -P-STAT5-A01), Glycogen synthase kinase-3 alpha/beta (GSK3A/B, Cat Nr: P-GSK3A/B-A01), 40 S ribosomal protein S6 (RS6, Cat Nr: P-RS6-A01), Ribosomal protein S6 kinase beta-1 (p70S6K, Cat Nr: p-KS6B1-A01), Platelet-derived growth factor receptor beta (PGFRb, Cat Nr: P-PDGFRb-A01), Tyrosine-protein kinase Lck (LCK, Cat Nr: P-LCK-A01), Ribosomal pro/, tein S6 kinase alpha-1 (RSK1, Cat Nr: P-KS6A1-A01), Nuclear factor erythroid 2-related factor 2 (NRF2, Cat Nr: P-NRF2-A01), Cyclic AMP-responsive element-binding protein 1 (CREB1, Cat Nr: P-CREB1-A01), Signal transducer and activator of transcription 6 (STAT6, Cat Nr: P-STAT6-A01), Focal adhesion kinase 1 (FAK1, Cat Nr: P-FAK1-A01), Proto-oncogene tyrosine-protein kinase SRC (SRC, Cat Nr: P-SRC-A01), NF-kappa-B inhibitor alpha (Ik-Ba, Cat Nr: P-NFkB-A01), Proline-rich AKT1 substrate 1 (AKTS1, Cat Nr: P-AKTS1-A01).

RNA isolation and Real-Time Polymerase Chain Reaction (RT-PCR). Total RNA was extracted from cells using QIAzol Lysis Reagent and quantification of gene expression was assessed by RT-PCR using the $\Delta \Delta \mathrm{Ct}$ method as described previously ${ }^{47}$. The sequences of the specific primers are described in Table 1.

Protein extraction and western blotting. Whole cell extracts were prepared using radio immunoprecipitation assay (RIPA) buffer containing a protease inhibitor cocktail tablet (Sigma) and western blot analysis was performed using standard immunoblotting protocols as described previously ${ }^{20,47}$. The detection of the 

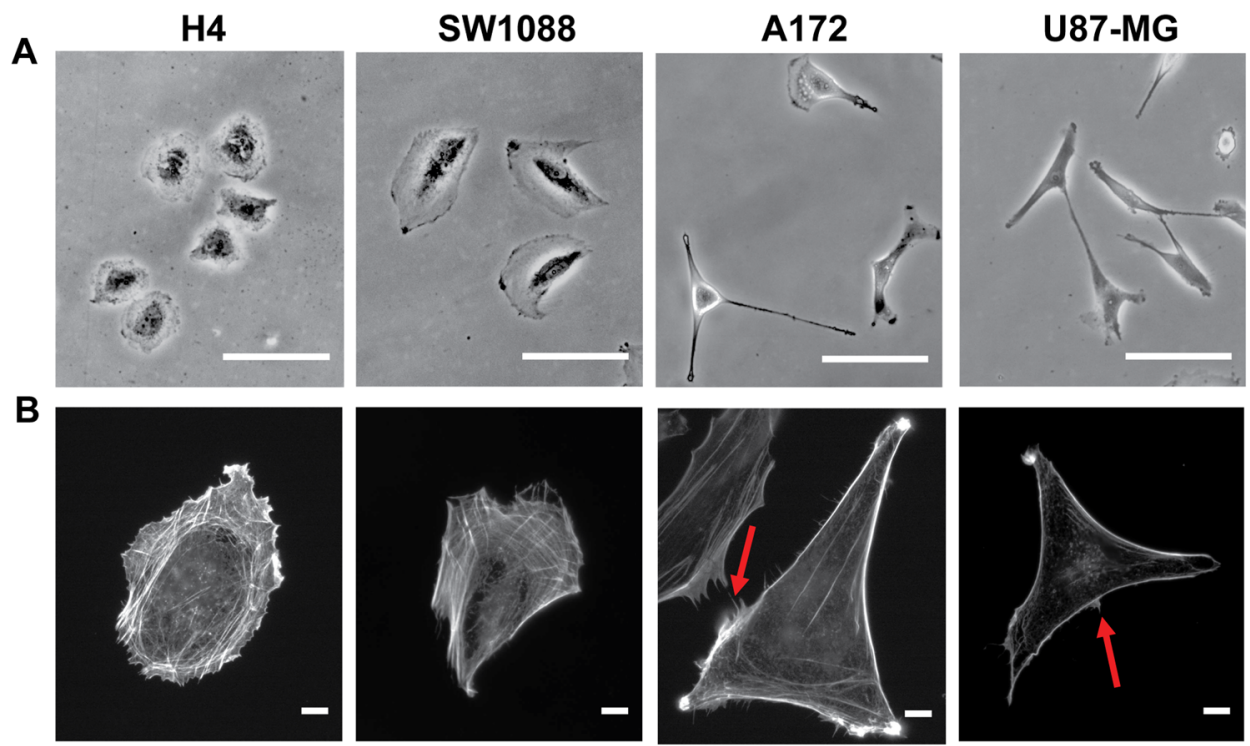

C
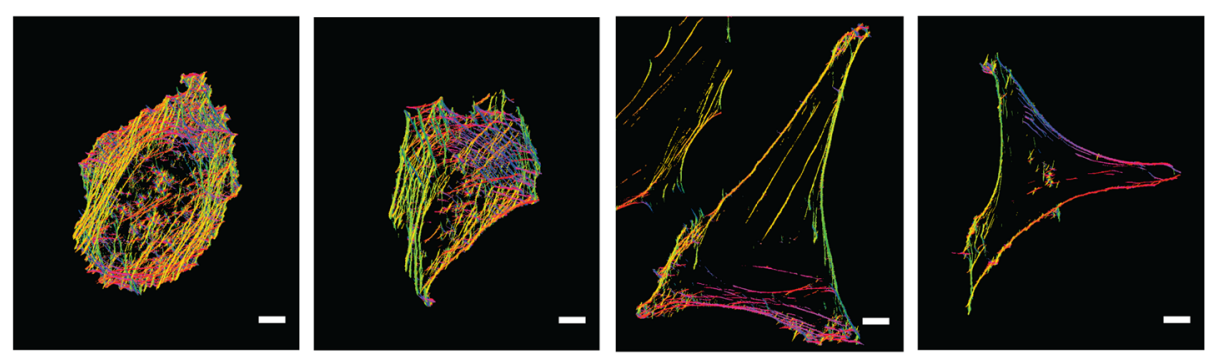

D

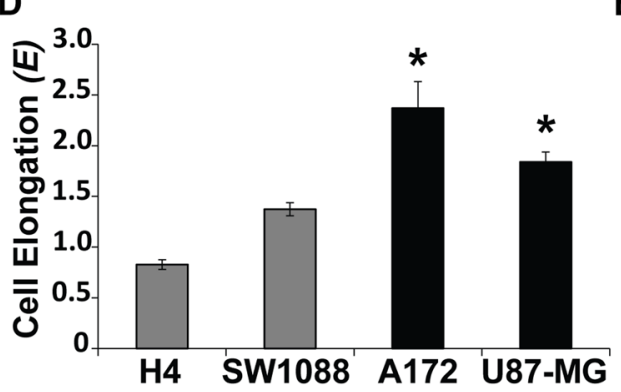

E

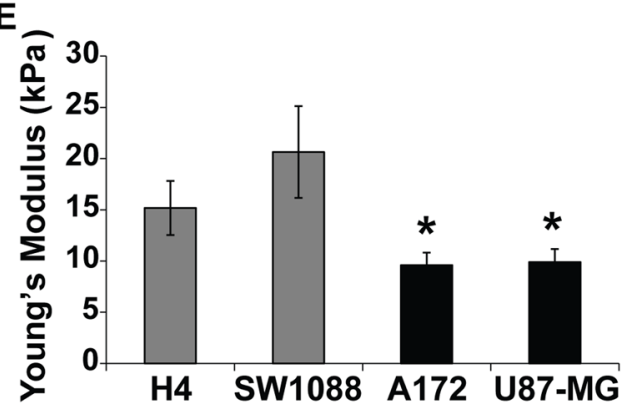

Figure 1. Morphological characterization of glioma cells. Representative images from (A) optical microscope imaging of H4, SW1088, A172 and U87-MG cells. Scale bar: $100 \mu \mathrm{m}$ (B) fluorescence microscope imaging of phalloidin-stained cells and (C) stress fiber orientation analysis using the FilamentSensor tool software where each color matches to a different fiber orientation $(n=30$ from each cell line and each group). Scale bar: $10 \mu \mathrm{m}$ (D) Cells elongation quantification, factor E was calculated from optical microscopy images of live cells, and (E) Young's modulus measurements using AFM. Asterisks denote a statistically significant difference $(\mathrm{p}<0.05)$ compared to $\mathrm{H} 4$ data.

antibody was done with enhanced chemiluminescent system from Pierce and Kodak Biomax light films or using ChemiDoc XRS + Imaging System (BioRad) and protein expression was quantified compared to the $\beta$-actin loading control using the ImageJ software. The mean intensity of respective protein bands from four different immunoblots was used for the quantification, as indicated.

Statistical analysis. Results are represented as mean \pm standard error (SE). Significant changes were determined by Student's $t$ test using two-tail distribution. Differences with $\mathrm{p}$ values $<0.05$ were considered as statistically significant (indicated by an asterisk *).

\section{Results}

Glioma cell morphology is associated with their invasive behavior. We first set out to characterize the four human glioma cell lines (H4, SW1088, A172 and U87-MG) with regard to their morphology and assess the possible connection that morphology may have with cell aggressiveness. Optical microscopy imaging and elongation analysis demonstrated that A172 and U87-MG cells, which cause GBM, were more elongated than H4 and SW1088, which are non-tumorigenic epithelial and fibroblast-like cells, respectively (Fig. 1A,D $)^{48-50}$. As 
A
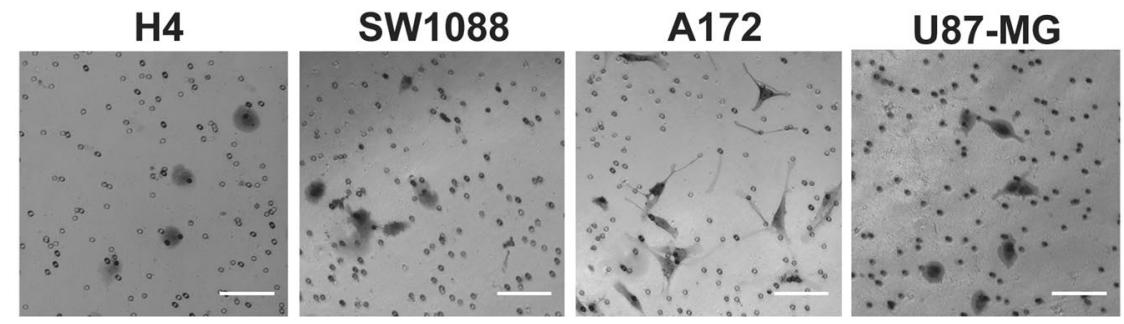

B
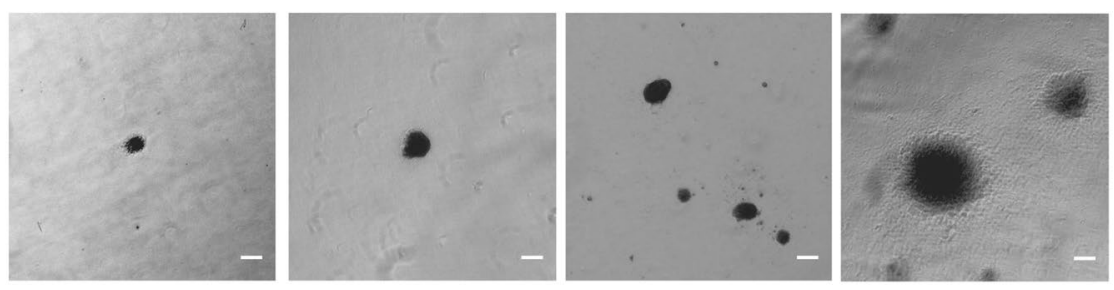

C

D

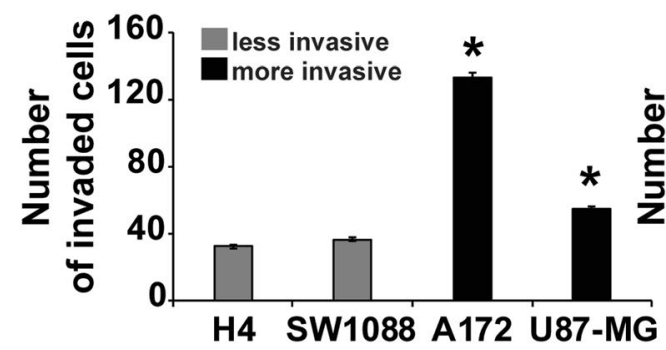

E
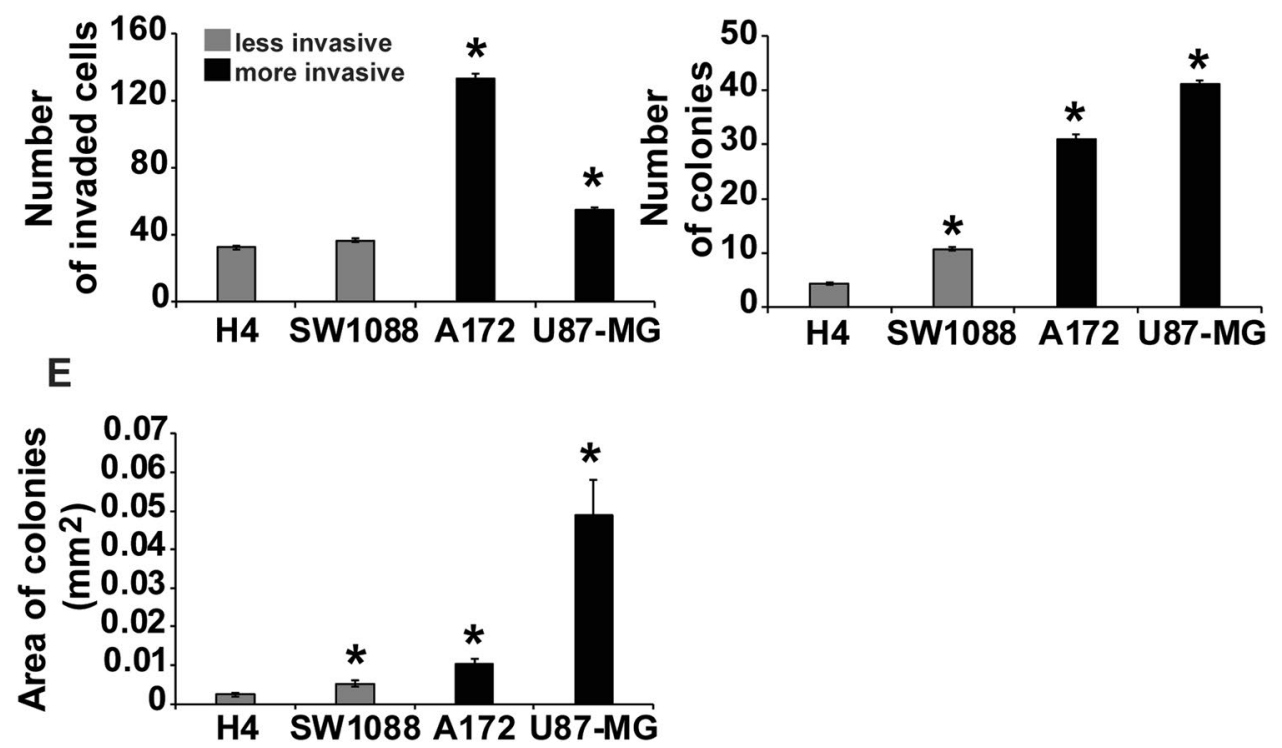

Figure 2. Aggressiveness of glioma cells. (A) Representative images of a transwell invasion assay using matrigel-coated inserts. The experiment was performed for $24 \mathrm{~h}$ and the invading cells were counted in nine (9) randomly chosen microscopic fields per transwell. (B) Representative images of soft agar assay for 30 days. For quantitative analysis, five (5) images per well were taken with inverted microscope. Scale bar:100 $\mu \mathrm{m}$. (C) Mean of total number of invaded cells per transwell of cell invasion compared to $\mathrm{H} 4$ cell line. Each sample was run in triplicate and three (3) independent experiments were performed. (D) Mean of total number of colonies per well compared to $\mathrm{H} 4$ cell line. Each sample was run in triplicate. (E) Area of colonies in $\mathrm{mm}^{2}$ in average per well. Asterisks denote a statistically significant difference $(\mathrm{p}<0.05)$ compared to $\mathrm{H} 4$ data.

cytoskeletal remodeling is fundamental for metastasis-related processes, such as migration and invasion ${ }^{51}$, cells were also stained with phalloidin, a widely-used fungal toxin known to bind filamentous actin, in order to detect possible changes in the organization of the cytoskeleton. Figure 1B shows that H4 and SW1088 cells exhibited abundant F-actin stress fibers in contrast to A172 and U87-MG cells where filamentous actin was not that prominent. Furthermore, we used the FilamentSensor tool software ${ }^{32}$ in order to investigate the stress fiber orientation in each cell line. As shown in Fig. 1C, stress fibers in H4 and SW1088 cells presented random orientation, while A172 and U87-MG exhibited well-organized actin fibers. Interestingly, A172 and U87-MG cells formed more lamellipodia, the thin sheet-like membrane protrusions found at the leading edge of migrating cells, as indicated by the arrow in Fig. 1B, suggesting that these two cell lines are more prone to migration.

Elongated and softer glioma cells are more invasive. Intrigued by the finding that A172 and U87-MG have morphological characteristics that differentiate them from $\mathrm{H} 4$ and SW1088, we sought to find out whether their stiffness was also related to their invasive potential. Several studies in the literature have connected these two, showing that the softer the cell the more likely it is to exhibit malignant characteristics ${ }^{30}$. For this purpose, AFM was used to measure cell stiffness of the four glioma cell lines. We found that A172 and U87-MG cells were softer than $\mathrm{H} 4$ and SW1088 (Fig. 1E), as demonstrated by the reduced Young's modulus value. The absolute values of the cell's Young's modulus were found to be H4:15.2 $\pm 2.6 \mathrm{kPa}, S W 1088: 20.6 \pm 4.5 \mathrm{kPa}, \mathrm{A} 172: 9.6 \pm 1.2 \mathrm{kPa}$ 
A

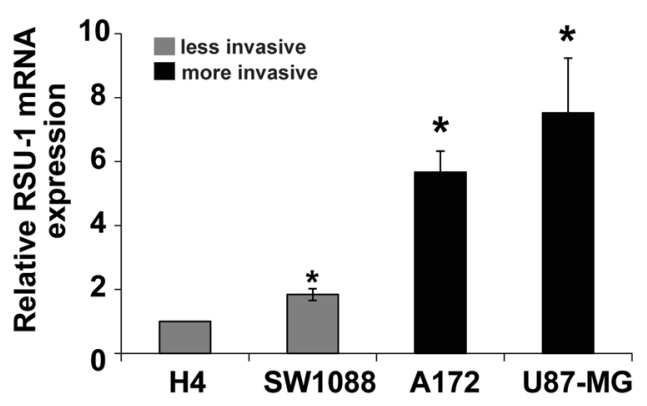

C

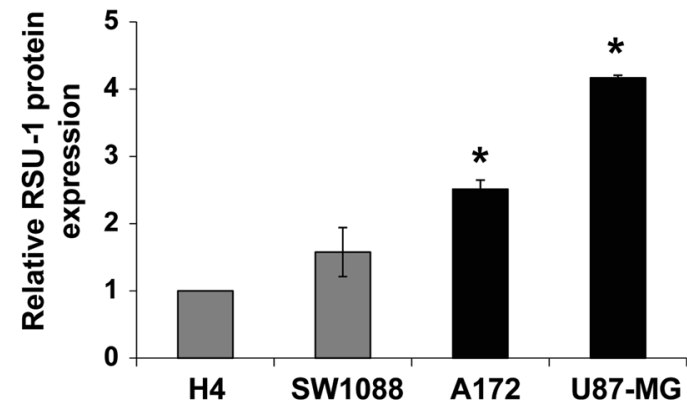

B

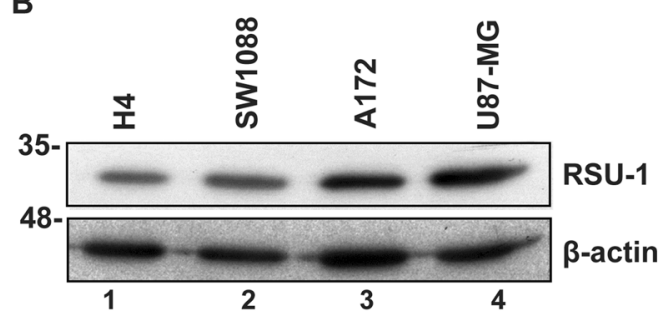

Figure 3. RSU-1 expression is elevated in more invasive glioma cells. (A) Relative RSU-1 mRNA expression for the four glioma cell lines under study. Four independent Real Time PCR experiments were performed, and data were analyzed using the $\Delta \Delta \mathrm{Ct}$ method. (B) Western blot for $R S U-1$ protein expression, using $\beta$-actin as a loading control and $\mathrm{H} 4$ as a sample control. Cropped blots are from samples run on the same gel and original pictures of the western blots are displayed in Supplementary Fig. 2. (C) Graph shows the quantification of $R S U-1$ protein expression by Image J software from three different western blots. Asterisks denote a statistically significant difference $(\mathrm{p}<0.05)$ compared to $\mathrm{H} 4$ data.

A

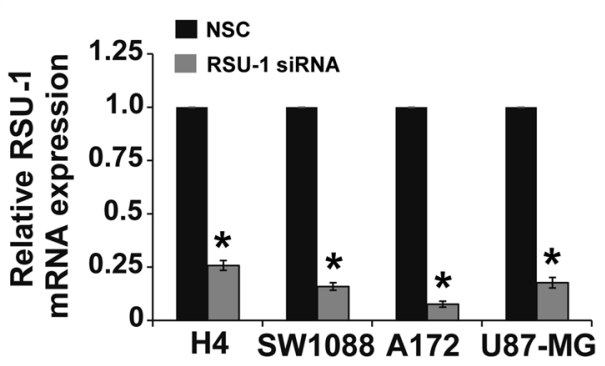

C

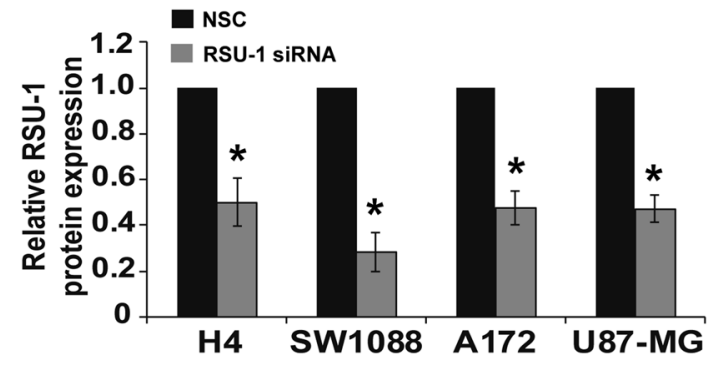

B

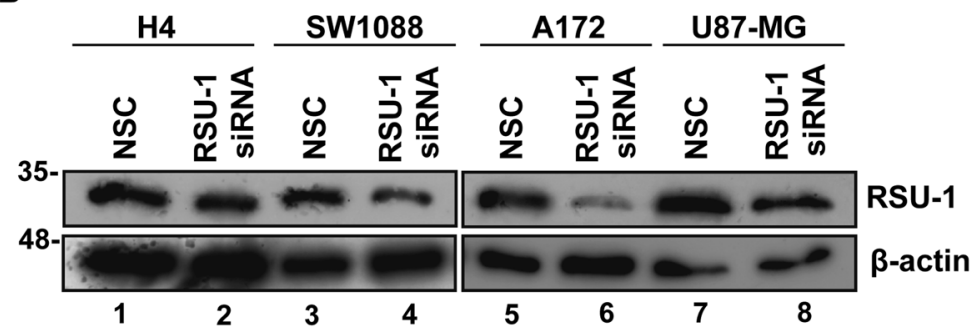

Figure 4. RSU-1 is effectively silenced both at the mRNA level and protein level. (A) Relative mRNA expression of RSU-1 in H4, SW1088, A172 and U87-MG cells upon treatment with NSC or RSU-1 siRNA for at least $48 \mathrm{~h}$. Eleven (11) independent RT-PCR experiments were performed and data were analyzed using the $\Delta \Delta \mathrm{Ct}$ method, having NSC treated cells as a calibrator sample for each cell line. (B) Representative immunoblot showing RSU1 expression at the protein level following treatment with NSC or RSU-1 siRNA in all four glioma cell lines studied. Cropped blots are from samples run on the same gel and original pictures of the western blots are displayed in Supplementary Fig. 3. (C) Graph representing quantification of RSU-1 protein expression normalized to $\beta$-actin for each cell line using ImageJ software. Immunoblots from four (4) independent experiments were used for the quantification. Asterisks denote a statistically significant difference $(\mathrm{p}<0.05)$ compared to NSC data. 
A
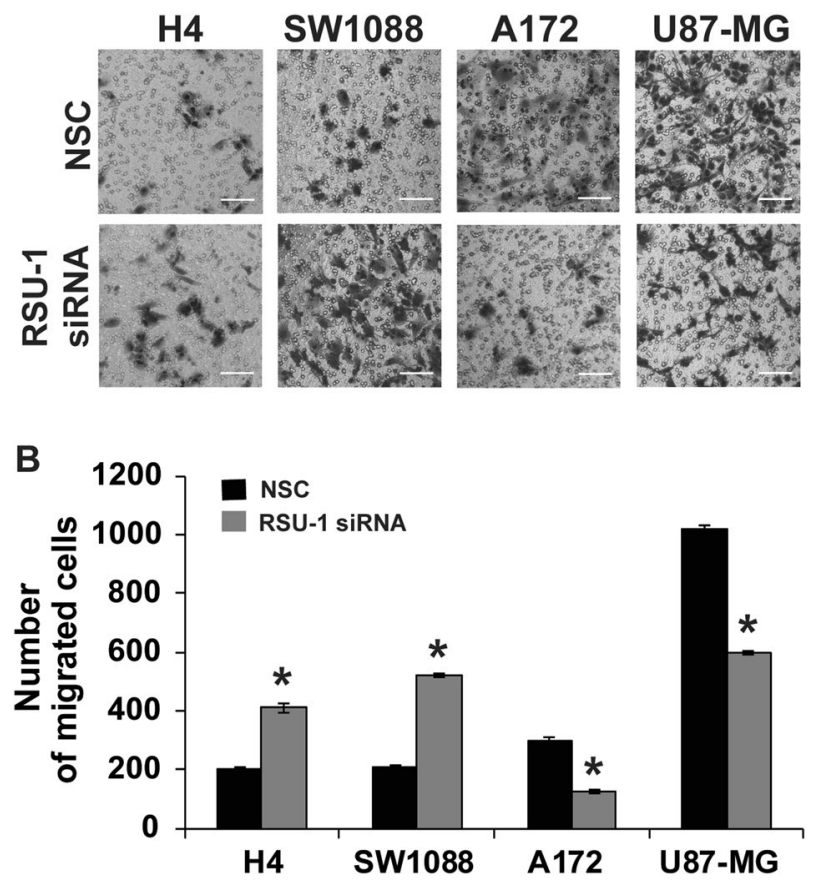

Figure 5. RSU-1 silencing increased migration of the non-aggressive glioma cells but decreased migration of the aggressive cells. (A) Representative images of a transwell migration assay that was performed for $24 \mathrm{~h}$ for the four glioma cell lines with NSC or RSU-1 siRNA treatment. Scale bar: $100 \mu \mathrm{m}$. The migrating cells were counted in nine (9) randomly chosen microscopic fields per transwell. (B) Total number of migrated cells compared to NSC for each cell line per transwell. Each sample was run in triplicate and three (3) independent experiments were performed. Asterisks denote a statistically significant difference $(\mathrm{p}<0.05)$ compared to NSC data.

and U87-MG:9.9 $\pm 1.3 \mathrm{kPa}$ (Young's Modulus Absolute Value $=$ Average \pm Standard Error), which lie within the expected values for live cells ${ }^{52,53}$.

To test our hypothesis that cell stiffness is related to malignant characteristics, such as cell migration and invasion, a transwell invasion assay was performed. Over a 24-h period, the number of cells that invaded through matrigel differed among the four glioma cell lines (Fig. 2A,C). The total number of cells invading through matrigel in average per transwell is presented in Fig. 2C. The more aggressive U87-MG and A172 cells showed a statistically significant increase in invasion compared to the less aggressive H4 and SW1088.

To corroborate the data obtained from the transwell invasion assay, glioma cancer cell spheroids were generated from all four cell lines under study and embedded in $1 \mathrm{mg} / \mathrm{ml}$ collagen I gels, as described previously ${ }^{20}$. Notably, the rate of tumor spheroid invasion was dramatically different between the cell lines, further verifying that A172 and U87-MG are more invasive than H4 and SW1088. Supplementary Fig. 1A shows representative images of H4 and A172 spheroids at their corresponding times. Specifically, A172 and U87-MG tumor spheroids invaded quickly and started dissociating from the original spheroid mass within $6 \mathrm{~h}$, while $\mathrm{H} 4$ spheroids reached a similar state at $16 \mathrm{~h}$, and SW1088 spheroids at $12 \mathrm{~h}$ (Supplementary Fig. 1B). Thus, the incubation time needed for spheroid invasion was correlated with the aggressiveness of cells and their invasive potential.

Aggressive cells construct colonies in unfavorable conditions. As our findings indicated that A172 and U87-MG cells were more elongated, softer, and formed tumor spheroids that invaded faster through collagen gels than H4 and SW 1088 cells, we next examined the degree of their aggressiveness using the standard soft agar assay (Fig. 2B). The number of colonies formed on soft agar by the four glioma cell lines at the end of the 30-day period was measured and results are shown in Fig. 2D. U87-MG and A172 cells formed multiple large colonies on agar, while the other two cell lines only formed a few small colonies (Fig. 2E). Notably, U87-MG cells formed colonies of the largest size. These results further confirm that A172 and U87-MG exhibit a more invasive phenotype than $\mathrm{H} 4$ and SW1088.

RSU-1 protein and mRNA expressions are elevated in the aggressive glioma cell lines. As RSU-1 has been previously reported to be overexpressed in metastatic breast cancer samples as well as highly invasive breast cancer and hepatocellular carcinoma cell lines ${ }^{19,54}$, we investigated if it is differentially expressed in our glioma cell lines and if its expression is correlated with invasiveness. In that regard, we first tested the expression of $R S U-1$ at the mRNA level. Real-Time PCR was performed for the RSU-1 gene using actin as housekeeping gene and $\mathrm{H} 4$ cell line as calibrator (Fig. 3A). Our results showed that the more aggressive A172 and U87-MG cell lines overexpressed RSU-1 compared to the less aggressive H4 and SW 1088 cell lines. Real-Time PCR results were also validated by immunoblotting (Fig. 3B,C, note lanes 3 and 4 compared to lanes 1 and 2, as well as Supplementary Fig. 4). 
A

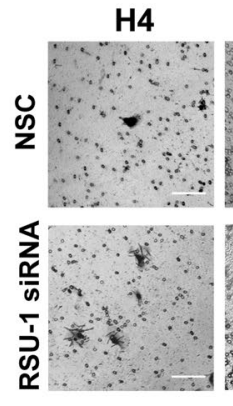

C

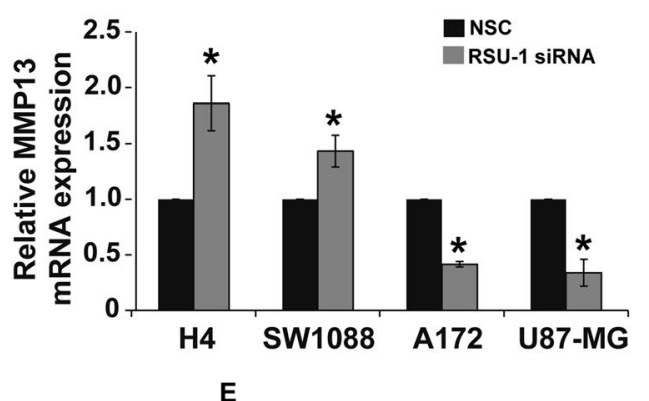

E
B

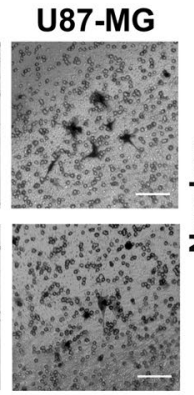

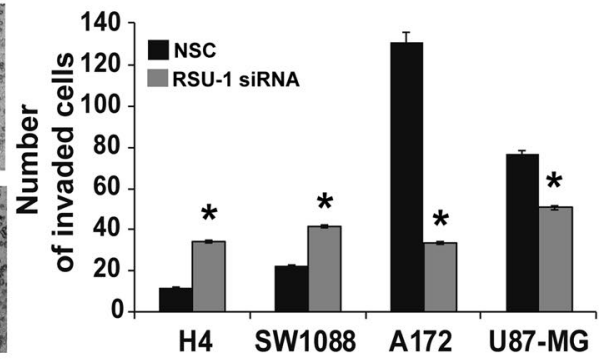

D

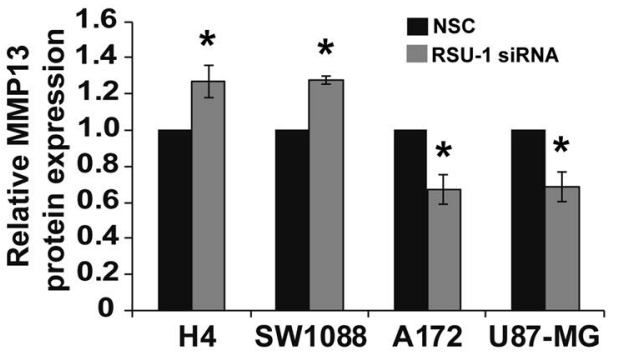

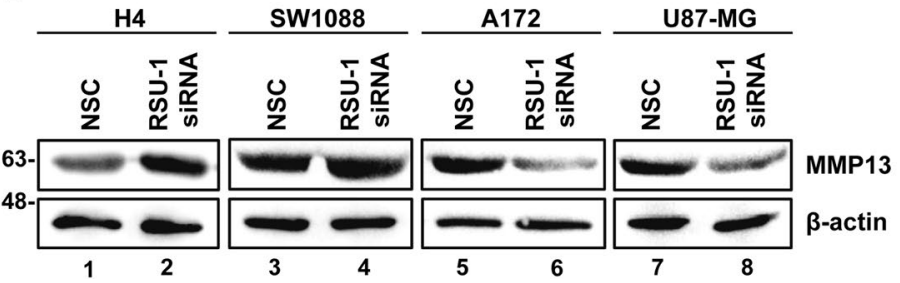

Figure 6. RSU-1 silencing increased invasion of non-aggressive glioma cells while decreased invasion of aggressive glioma cells through reduction in MMP-13. (A) Representative images of a transwell invasion assay that was performed for $24 \mathrm{~h}$ for the four glioma cell lines with NSC or RSU-1 siRNA treatment. The invading cells were counted in nine (9) randomly chosen microscopic fields per transwell. Scale bar: $100 \mu \mathrm{m}$. (B) Total number of invaded cells compared to NSC for each cell line per transwell. Each sample was run in triplicate and at least three (3) independent experiments were performed. (C) Relative MMP13 mRNA expression following RSU-1 silencing for the four studying glioma cells was measured by RT-PCR and quantification was done using as NSC as the calibrator sample. (D) Graph representing quantification of MMP13 protein expression normalized to $\beta$-actin for each cell line following treatment with NSC or RSU-1 siRNA in all four glioma cell lines studied. Immunoblots from three independent experiments were used for the quantification using ImageJ software. (E) Representative immunoblot showing MMP13 protein expression. Original pictures of the western blots are displayed in Supplementary Fig. 6. Asterisks denote a statistically significant difference $(\mathrm{p}<0.05)$ compared to NSC data.

Elimination of RSU-1 from glioma cells differentially affects their motility. To identify the role of RSU-1 in the metastatic properties of glioma cells, it was silenced using siRNA-mediated silencing using a non-specific control siRNA (NSC) as transfection control. RSU-1 was effectively silenced both at the mRNA (Fig. 4A) and protein (Fig. 4B,C) level. Then, transwell migration assay was performed to find out how RSU-1 silencing affects cell motility. The number of cells that migrated through the transwell pores was counted $24 \mathrm{~h}$ after the addition of cells in the transwell and $48 \mathrm{~h}$ after siRNA transfection. Surprisingly, RSU-1 silencing did not have the same effect in all four glioma cell lines tested. Interestingly enough though, the migratory response of cells was associated with the degree of malignancy to which we assigned them based on the results of morphological analysis, AFM measurements, soft agar growth and spheroid invasion. The least aggressive glioma cells ( $\mathrm{H} 4$ and SW1088) exhibited increased motility following RSU-1 silencing in contrast to the most aggressive glioma cells (A172 and U87-MG), which exhibited decreased motility after RSU-1 silencing (Fig. 5A,B).

RSU-1 enhances the invasion potential of aggressive glioma cells through MMP13, in contrast to non-aggressive glioma cells. Next, transwell invasion assay was performed following RSU-1 silencing in all glioma cell lines. In accordance with cell motility results, invasion capacity was also found to be decreased upon RSU-1 silencing in the most aggressive glioma cells, whereas it was increased in the least aggressive cells (Fig. 6A). Figure 6B indicates the mean of the total number of invaded cells per transwell for each cell line upon $R S U-1$ silencing. 
A

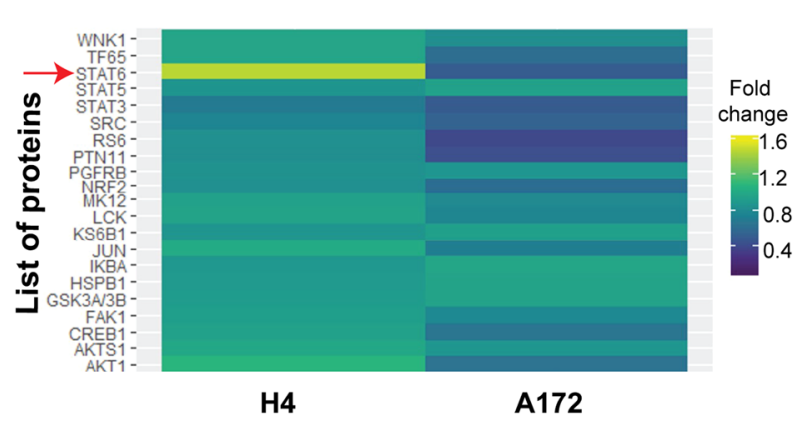

B

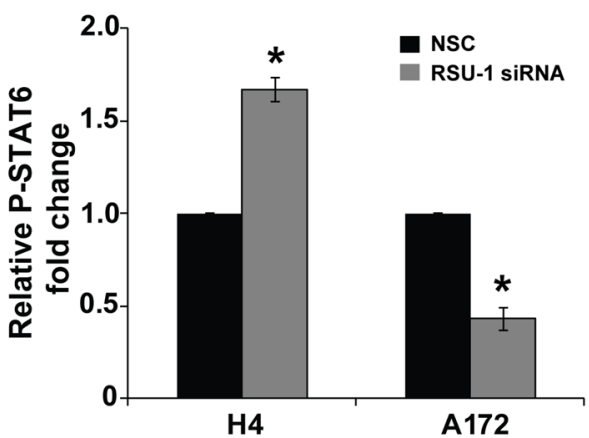

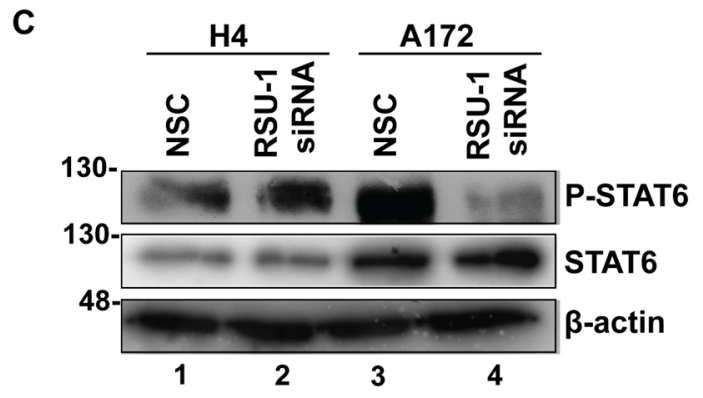

Figure 7. RSU-1 silencing enhanced STAT6 phosphorylation in non-aggressive glioma cells while diminished STAT6 phosphorylation in aggressive glioma cells. (A) The heatmap depicts mean fold change results from the phosphoproteomic analysis performed for 21 phospho-proteins in two independent experiments between the treated (RSU-1 siRNA) and control cells (NSC siRNA) for both H4 and A172 cell lines. Red arrow indicates the most significant change in phosphorylation status upon RSU-1 knockdown. (B) Quantification of the phosphoprotein analysis data for P-STAT6 following $R S U-1$ silencing using NSC as the control sample. (C) Representative immunoblot validating the phosphorylation status of STAT6 for the same protein samples as in (A). Cropped blots are from samples run on the same gel and original pictures of the western blots are displayed in Supplementary Fig. 8. Asterisks denote a statistically significant difference $(\mathrm{p}<0.05)$ compared to NSC.

Finally, we tested whether RSU-1 silencing affects key molecules involved in matrix degradation, an important aspect of cell invasion. Thus, following RSU-1 silencing, we tested the mRNA expression of matrix metalloproteinase13 (MMP13) a fundamental protease in cancer cell metastasis, known to be involved in collagen I degradation ${ }^{55,56}$ that was previously shown to be regulated by $R S U-1$ silencing in breast cancer cells ${ }^{20}$. We found that MMP13 mRNA expression was following a pattern identical to that of cell migration and invasion, corroborating our findings (Fig. 6C). Quantitative PCR results were validated further at the protein level by immunoblotting as shown in Fig. 6D,E.

Rsu-1 silencing exerts its effect on glioma cell invasion through STAT6 phosphorylation regulation. Although the connection between cell invasion and MMP13 expression is well-established, we investigated whether other signaling molecules are mediating the effect of RSU-1 silencing on cell invasion. To that regard, we selected the least invasive (H4) and one of the most invasive (A172) cells from the glioma cell panel, treated them with NSC or $R S U-1$ siRNA and analyzed their protein expression using a Multiplexed Assay specifically designed to detect the 21 most influential phospho-proteins. Analysis of the Multiplex assay (Fig. 7A) showed that only Signal Transducer and Activator of Transcription6 (STAT6) exhibited changes in phosphorylation that were consistent with the observed invasion pattern as well as with recently published data showing STAT6 to promote invasion in glioma cells ${ }^{57}$. More specifically, the least invasive cells (H4) treated with $R S U-1$ siRNA had an increased level of phospho-STAT6 and a more invasive potential (Fig. 7B), whereas the more invasive cells (A172) treated with $R S U-1$ siRNA exhibited decreased phospho-STAT6 levels and a less invasive capacity (Fig. 7A,B). The multiplex assay results were validated further by immunoblotting for H4 and A172 cell lines (Fig. 7C) as well as SW1088 and U87-MG cell lines (Supplementary Fig. 7). To test whether STAT- 6 phosphorylation is crucially involved in glioma cell invasion, we inhibited it in H4 and A172 cells by varying the concentration $(100,200 \& 300 \mathrm{nM})$ of the AS1517499 inhibitor, and we found that their invasive capacity was reduced upon inhibition of STAT- 6 phosphorylation in a dose-dependent manner in both cell lines (Fig. 8A,B). These results were then validated in SW1088 and U87-MG cells using only the optimum concentration of the AS1517499 (300 nM) as shown in Supplementary Fig. 11.

\section{Discussion}

In the current study, we used four glioma cell lines, namely H4, SW1088, U87-MG and A172 ${ }^{48-50,58}$ and we first characterized them based on their morphology, actin cytoskeleton organization, stiffness and invasion capacity. Our results show that A172 and U87-MG cells, which cause malignant tumors, were more elongated (Fig. 1A), exhibited well-organized actin fibers, increased invasion in transwells and in collagen-embedded spheroids 
A

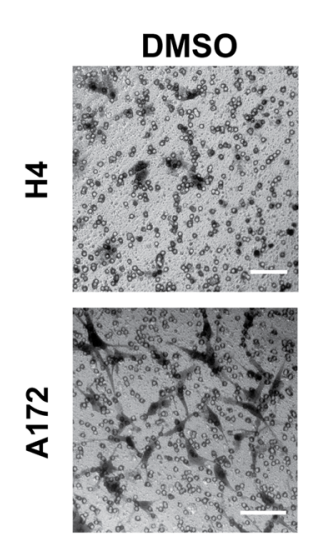

B

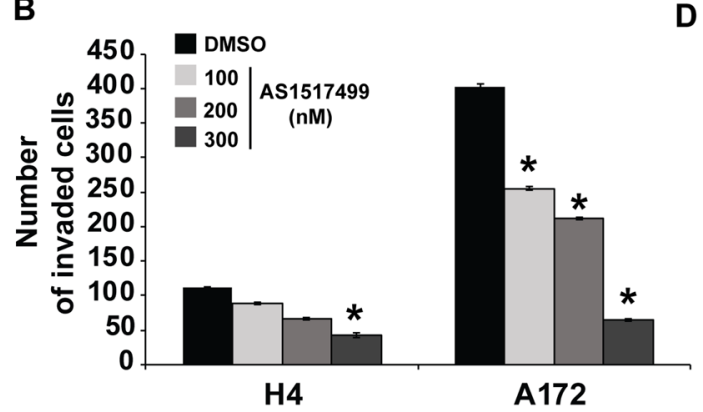

C

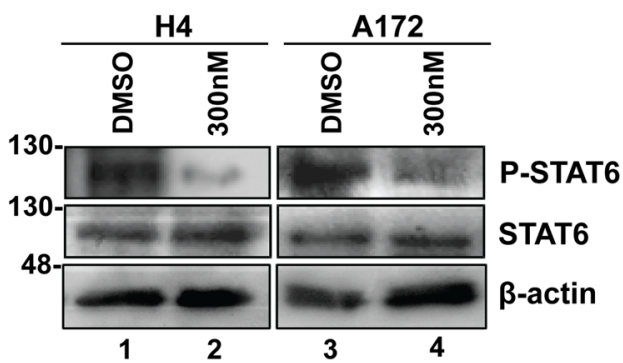

D
AS1517499 (nM)

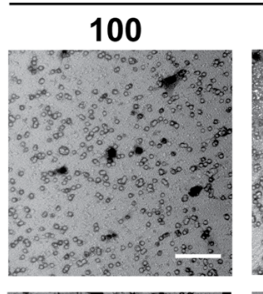

200
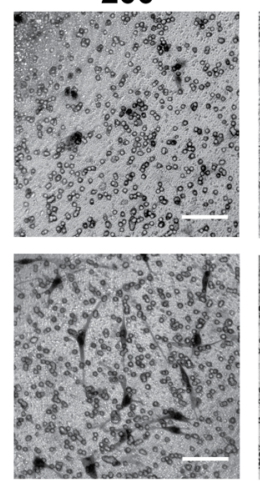
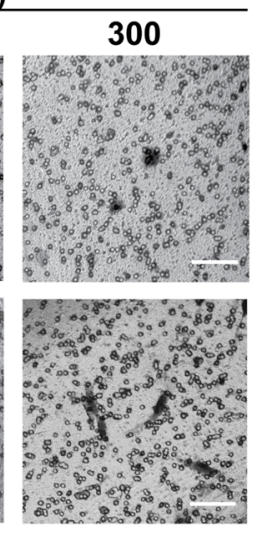

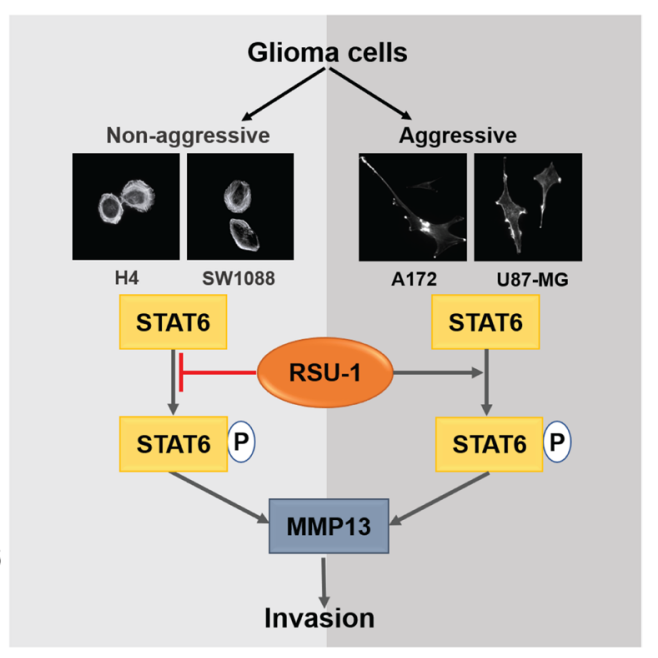

Figure 8. In vitro effects of the phospho-STAT6 inhibitor (AS1517499), in glioma cell (H4 and A172) invasion. (A) Representative images of transwell invasion assay performed following treatment with phospho-STAT6 inhibitor, AS1517499 (at 100, 200 or $300 \mathrm{nM}$ ) or DMSO for $24 \mathrm{~h}$. Cells were left to invade for an additional $24 \mathrm{~h}$ time period with inhibitor. The invading cells were counted in nine (9) randomly chosen microscopic fields per transwell. Scale bar: $100 \mu \mathrm{m}$. (B) Total number of invaded cells compared to DMSO for each cell line per transwell. Two transwells were included per sample and at least two (2) independent experiments were performed. (C) Representative images of Western blot results of STAT6 phosphorylation in glioma cell lines (H4 and A172) following treatment with DMSO or $300 \mathrm{nM}$ of AS1517499. Original pictures of the western blots are displayed in Supplementary Fig. 10. Asterisks denote a statistically significant difference $(p<0.05)$ compared to DMSO. (D) Schematic diagram illustrating the significant findings of this work.

(Fig. 2A, Supplementary Fig. 1) and increased formation of colonies in soft agar (Fig. 2B) showing metastatic abilities and capability for anchorage independent growth, respectively. Conversely, H4 and SW1088 cells were less elongated (Figs. 1A,D), presented random orientation of actin stress fibers (Fig. 1C), reduced invasion (Fig. 2A) and inability to grow in soft agar (Fig. 2B). Moreover, AFM measurements demonstrated that A172 and U87-MG cells exhibited statistically significant lower Young's modulus than H4 and SW1088, indicating that malignant glioma cells are softer than $\mathrm{H} 4$ and SW1088 a property that enables them to migrate faster (Fig. 1E). These findings are consistent with the results of pertinent studies in other cancer cell lines, which also showed that highly aggressive cancer cells are generally softer than non-malignant cells ${ }^{53,59,60}$. Interesting, the ratio of the Young's modulus value of the less invasive cells (non-tumorigenic, H4) to the Young's value of the other cell lines are: $\mathrm{H} 4 / \mathrm{SW} 1088=0.73, \mathrm{H} 4 / \mathrm{A} 172=1.58, \mathrm{H} 4 / \mathrm{U} 87-\mathrm{MG}=1.53$. These results are similar to the results found in the literature ${ }^{53,61}$ and especially to the ratio (1.4-1.8) between healthy and breast cancer cells where similar spherical probes were used ${ }^{62}$. We then tested the expression of RSU-1, a FA protein that was previously shown to be implicated in breast cancer cell invasion promoting breast cancer cell metastasis, introducing RSU-1 as a potential metastasis marker ${ }^{20}$. We found here that $R S U-1$ is upregulated in cell lines exhibiting higher invasion capacity (A172 and U87-MG) compared to the less invasive cells (H4 and SW1088) both at the mRNA (Fig. 3A) and protein level (Fig. 3B,C). Interestingly, we showed for the first time that RSU-1 silencing has an opposite effect 
on glioma cell line invasion depending on whether the cell line is aggressive or not (Fig. 6A,B). More specifically, $R S U-1$ silencing in A172 and U87-MG cell lines inhibited their invasion, whereas it promoted invasion of $\mathrm{H} 4$ and SW1088 cells. Interestingly, MMP13 expression followed an almost identical pattern (Fig. 6C,D). Finally, we also showed through multiplex analysis of phospho-proteins that STAT6 phosphorylation was increased in the $\mathrm{H} 4$ cell line upon RSU-1 silencing in contrast to A172 cells in which STAT6 phosphorylation was decreased (Fig. 7A,B). Multiplex results were validated by immunoblotting further confirming the involvement of STAT6 in glioma cell invasion (Fig. 7C) as demonstrated in other cancer types ${ }^{63}$. Interestingly, we also found that the invasive capacity of $\mathrm{H} 4$ and A172 glioma cells was decreased following inhibition of STAT6 phosphorylation in a dose-dependent manner (Fig. 8A,B). This result is in accordance with other previously published studies, showing that STAT-6 promotes glioma cells invasion ${ }^{57}$, although this is the first time that $R S U-1$ is being associated with STAT6 regulation as shown in Fig. 7D.

In conclusion, the present study provides the first evidence that RSU-1 has distinct roles in glioma cell invasion depending on the cells' aggressiveness. In fact, our finding that depletion of RSU-1 from the highly invasive A172 cells -that normally express RSU-1 in high levels- inhibits cell invasion, whereas depletion of $R S U-1$ from the non-invasive $\mathrm{H} 4$ cells -that normally express RSU-1 at minimal levels-enhances cell invasion indicates that there exists a type of regulation that is level-dependent. This is reminiscent of other cases in which the expression level of a FA protein is correlated with differential regulation of cell migration ${ }^{64}$, and definitely warrants further investigation. Further investigation is, of course, warranted in order to decipher the exact mechanism of action of RSU-1 in gliomas. Moreover, validation of the current findings in human glioma patients, especially of varying tumor grade would be rather valuable and might render RSU-1 a predictor of gliomas progression potentially contributing to the development of novel therapeutic interventions targeting it. Hence, patients with elevated $R S U-1$ expression would be expected to have aggressive gliomas and would benefit from a treatment that includes blocking $R S U-1$ whereas patients with reduced $R S U-1$ expression would be expected to have less aggressive tumors and would thus benefit from a conventional treatment.

\section{References}

1. Buckner, J. C. et al. Central nervous system tumors. Mayo Clin Proc 82, 1271-1286, https://doi.org/10.4065/82.10.1271 (2007).

2. Ma, Y. S. et al. DRR1 promotes glioblastoma cell invasion and epithelial-mesenchymal transition via regulating AKT activation. Cancer letters 423, 86-94, https://doi.org/10.1016/j.canlet.2018.03.015 (2018).

3. de Groot, J. F. et al. Tumor invasion after treatment of glioblastoma with bevacizumab: radiographic and pathologic correlation in humans and mice. Neuro Oncol 12, 233-242, https://doi.org/10.1093/neuonc/nop027 (2010).

4. Johnson, D. R. \& O'Neill, B. P. Glioblastoma survival in the United States before and during the temozolomide era. J Neurooncol 107, 359-364, https://doi.org/10.1007/s11060-011-0749-4 (2012).

5. Stupp, R. et al. Radiotherapy plus concomitant and adjuvant temozolomide for glioblastoma. N Engl J Med 352, 987-996, https://doi. org/10.1056/NEJMoa043330 (2005).

6. Scherer, H. The forms of growth in gliomas and their practical significance. Brain 63, 1-35 (1940).

7. Sun, L. H. et al. Overexpression of Paxillin Correlates with Tumor Progression and Predicts Poor Survival in Glioblastoma. CNS Neurosci Ther 23, 69-75, https://doi.org/10.1111/cns.12606 (2017).

8. Zaidel-Bar, R., Itzkovitz, S., Ma'ayan, A., Iyengar, R. \& Geiger, B. Functional atlas of the integrin adhesome. Nat Cell Biol 9, 858-867, https://doi.org/10.1038/ncb0807-858 (2007).

9. Bokel, C. \& Brown, N. H. Integrins in development: moving on, responding to, and sticking to the extracellular matrix. Dev Cell 3, 311-321 (2002).

10. Hoffmann, M. \& Schwarz, U. S. A kinetic model for RNA-interference of focal adhesions. BMC Syst Biol 7, 2, https://doi. org/10.1186/1752-0509-7-2 (2013).

11. Masuelli, L. \& Cutler, M. L. Increased expression of the Ras suppressor Rsu-1 enhances Erk-2 activation and inhibits Jun kinase activation. Mol Cell Biol 16, 5466-5476 (1996).

12. Cutler, M. L., Bassin, R. H., Zanoni, L. \& Talbot, N. Isolation of Rsp-1, a Novel Cdna Capable of Suppressing V-Ras Transformation. Molecular and Cellular Biology 12, 3750-3756 (1992).

13. Donthamsetty, S. et al. Role of PINCH and its partner tumor suppressor Rsu-1 in regulating liver size and tumorigenesis. PLoS One 8, e74625, https://doi.org/10.1371/journal.pone.0074625 (2013).

14. Tsuda, T. \& Cutler, M. L. Human RSU1 is highly homologous to mouse Rsu-1 and localizes to human chromosome 10. Genomics 18, 461-462, https://doi.org/10.1006/geno.1993.1503 (1993).

15. Tsuda, T., Marinetti, M. R., Masuelli, L. \& Cutler, M. L. The Ras suppressor RSU-1 localizes to 10p13 and its expression in the U251 glioblastoma cell line correlates with a decrease in growth rate and tumorigenic potential. Oncogene 11, 397-403 (1995).

16. Vasaturo, F., Dougherty, G. W. \& Cutler, M. L. Ectopic expression of Rsu-1 results in elevation of p21CIP and inhibits anchorageindependent growth of MCF7 breast cancer cells. Breast Cancer Res Treat 61, 69-78 (2000).

17. Dougherty, G. W., Chopp, T., Qi, S. M. \& Cutler, M. L. The Ras suppressor Rsu-1 binds to the LIM 5 domain of the adaptor protein PINCH1 and participates in adhesion-related functions. Exp Cell Res 306, 168-179, https://doi.org/10.1016/j.yexcr.2005.01.025 (2005).

18. Dougherty, G. W., Jose, C., Gimona, M. \& Cutler, M. L. The Rsu-1-PINCH1-ILK complex is regulated by Ras activation in tumor cells. Eur J Cell Biol 87, 721-734, https://doi.org/10.1016/j.ejcb.2008.02.011 (2008).

19. Gkretsi, V. \& Bogdanos, D. P. Elimination of Ras Suppressor-1 from hepatocellular carcinoma cells hinders their in vitro metastatic properties. Anticancer Res 35, 1509-1512 (2015).

20. Gkretsi, V., Stylianou, A., Louca, M. \& Stylianopoulos, T. Identification of Ras suppressor-1 (RSU-1) as a potential breast cancer metastasis biomarker using a three-dimensional in vitro approach. Oncotarget 8, 27364-27379, https://doi.org/10.18632/ oncotarget.16062 (2017).

21. Gonzalez-Nieves, R., Desantis, A. I. \& Cutler, M. L. Rsul contributes to regulation of cell adhesion and spreading by PINCH1dependent and - independent mechanisms. J Cell Commun Signal 7, 279-293, https://doi.org/10.1007/s12079-013-0207-5 (2013).

22. Zacharia, L. C., Stylianopoulos, T. \& Gkretsi, V. Ras Suppressor-1 (RSU-1) in Cancer Cell Metastasis: Friend or Foe? Crit Rev Oncog 22, 249-253, https://doi.org/10.1615/CritRevOncog.2018024231 (2017).

23. Chunduru, S. et al. Identification of an alternatively spliced RNA for the Ras suppressor RSU-1 in human gliomas. J Neurooncol 60, 201-211 (2002).

24. Pierron, M., Pinan-Lucarre, B. \& Bessereau, J. L. Preventing Illegitimate Extrasynaptic Acetylcholine Receptor Clustering Requires the RSU-1 Protein. J Neurosci 36, 6525-6537, https://doi.org/10.1523/JNEUROSCI.3733-15.2016 (2016).

25. Masuelli, L., Ettenberg, S., Vasaturo, F., Vestergaard-Sykes, K. \& Cutler, M. L. The ras suppressor, RSU-1, enhances nerve growth factor-induced differentiation of PC12 cells and induces p21CIP expression. Cell Growth Differ 10, 555-564 (1999). 
26. Porcheri, C., Suter, U. \& Jessberger, S. Dissecting integrin-dependent regulation of neural stem cell proliferation in the adult brain. J Neurosci 34, 5222-5232, https://doi.org/10.1523/JNEUROSCI.4928-13.2014 (2014).

27. Stylianou, A. \& Yova, D. Surface nanoscale imaging of collagen thin films by Atomic Force Microscopy. Mater Sci Eng C Mater Biol Appl 33, 2947-2957, https://doi.org/10.1016/j.msec.2013.03.029 (2013).

28. Yim, E. K. et al. Nanopattern-induced changes in morphology and motility of smooth muscle cells. Biomaterials 26, 5405-5413, https://doi.org/10.1016/j.biomaterials.2005.01.058 (2005).

29. Stylianou, A. \& Yova, D. Atomic force microscopy investigation of the interaction of low-level laser irradiation of collagen thin films in correlation with fibroblast response. Lasers Med Sci 30, 2369-2379, https://doi.org/10.1007/s10103-015-1823-5 (2015).

30. Stylianou, A., Gkretsi, V. \& Stylianopoulos, T. Transforming growth factor-beta modulates pancreatic cancer associated fibroblasts cell shape, stiffness and invasion. Biochimica et biophysica acta. https://doi.org/10.1016/j.bbagen.2018.02.009 (2018).

31. Hermanowicz, P., Sarna, M., Burda, K. \& Gabrys, H. AtomicJ: an open source software for analysis of force curves. Rev Sci Instrum 85, 063703, https://doi.org/10.1063/1.4881683 (2014).

32. Eltzner, B., Wollnik, C., Gottschlich, C., Huckemann, S. \& Rehfeldt, F. The filament sensor for near real-time detection of cytoskeletal fiber structures. PLoS One 10, e0126346, https://doi.org/10.1371/journal.pone.0126346 (2015).

33. Gu, H. et al. Celastrus orbiculatus extract inhibits the migration and invasion of human glioblastoma cells in vitro. BMC Complement Altern Med 16, 387, https://doi.org/10.1186/s12906-016-1232-8 (2016).

34. Xue, H. et al. MicroRNA-584-3p, a novel tumor suppressor and prognostic marker, reduces the migration and invasion of human glioma cells by targeting hypoxia-induced ROCK1. Oncotarget 7, 4785-4805, https://doi.org/10.18632/oncotarget.6735 (2016).

35. Gong, L. et al. Overexpression of MYC binding protein promotes invasion and migration in gastric cancer. Oncol Lett 15, 5243-5249, https://doi.org/10.3892/ol.2018.7944 (2018).

36. Wang, K., Jin, W., Song, Y. \& Fei, X. LncRNA RP11-436H11.5, functioning as a competitive endogenous RNA, upregulates BCL-W expression by sponging miR-335-5p and promotes proliferation and invasion in renal cell carcinoma. Mol Cancer 16, 166, https:// doi.org/10.1186/s12943-017-0735-3 (2017).

37. Chen, L. et al. Expression and function of miR-27b in human glioma. Oncol Rep 26, 1617-1621, https://doi.org/10.3892/or.2011.1458 (2011).

38. Wen, M. et al. Cytokine-like 1 is involved in the growth and metastasis of neuroblastoma cells. Int J Oncol 41, 1419-1424, https://doi. org/10.3892/ijo.2012.1552 (2012).

39. Gao, S. et al. Overexpression of RASD1 inhibits glioma cell migration/invasion and inactivates the AKT/mTOR signaling pathway. Sci Rep 7, 3202, https://doi.org/10.1038/s41598-017-03612-0 (2017).

40. Del Duca, D., Werbowetski, T. \& Del Maestro, R. F. Spheroid preparation from hanging drops: characterization of a model of brain tumor invasion. J Neurooncol 67, 295-303 (2004).

41. Foty, R. A simple hanging drop cell culture protocol for generation of 3D spheroids. J Vis Exp. https://doi.org/10.3791/2720 (2011).

42. Kelm, J. M., Timmins, N. E., Brown, C. J., Fussenegger, M. \& Nielsen, L. K. Method for generation of homogeneous multicellular tumor spheroids applicable to a wide variety of cell types. Biotechnol Bioeng 83, 173-180, https://doi.org/10.1002/bit.10655 (2003).

43. Binnemars-Postma, K., Bansal, R., Storm, G. \& Prakash, J. Targeting the Stat 6 pathway in tumor-associated macrophages reduces tumor growth and metastatic niche formation in breast cancer. FASEB journal: official publication of the Federation of American Societies for Experimental Biology 32, 969-978, https://doi.org/10.1096/fi.201700629R (2018).

44. Nappo, G. et al. The immunosuppressive cytokine interleukin-4 increases the clonogenic potential of prostate stem-like cells by activation of STAT6 signalling. Oncogenesis 6, e342, https://doi.org/10.1038/oncsis.2017.23 (2017).

45. da Silva, R., Uno, M., Marie, S. K. \& Oba-Shinjo, S. M. LOX expression and functional analysis in astrocytomas and impact of IDH1 mutation. PLoS One 10, e0119781, https://doi.org/10.1371/journal.pone.0119781 (2015).

46. Wang, J. et al. Involvement of microRNA-1297, a new regulator of HMGA1, in the regulation of glioma cell growth in vivo and in vitro. Am J Transl Res 8, 2149-2158 (2016).

47. Kalli, M., Papageorgis, P., Gkretsi, V. \& Stylianopoulos, T. Solid Stress Facilitates Fibroblasts Activation to Promote Pancreatic Cancer Cell Migration. Ann Biomed Eng 46, 657-669, https://doi.org/10.1007/s10439-018-1997-7 (2018).

48. Debinski, W. \& Gibo, D. M. Fos-related antigen 1 modulates malignant features of glioma cells. Mol Cancer Res 3, 237-249, https:// doi.org/10.1158/1541-7786.MCR-05-0004 (2005).

49. Dixit, V. D. et al. Ghrelin and the growth hormone secretagogue receptor constitute a novel autocrine pathway in astrocytoma motility. The Journal of biological chemistry 281, 16681-16690, https://doi.org/10.1074/jbc.M600223200 (2006).

50. Vereb, G. Jr. et al. Depletion of intracellular calcium stores facilitates the influx of extracellular calcium in platelet derived growth factor stimulated A172 glioblastoma cells. Cytometry 24, 64-73, doi:10.1002/(SICI)1097-0320(19960501)24:1<64::AIDCYTO8>3.0.CO;2-I (1996)

51. Hotulainen, P. \& Lappalainen, P. Stress fibers are generated by two distinct actin assembly mechanisms in motile cells. J Cell Biol 173, 383-394, https://doi.org/10.1083/jcb.200511093 (2006).

52. Radmacher, M. Measuring the elastic properties of living cells by the atomic force microscope. Methods in cell biology 68, 67-90 (2002).

53. Lekka, M. Discrimination Between Normal and Cancerous Cells Using AFM. Bionanoscience 6, 65-80, https://doi.org/10.1007/ s12668-016-0191-3 (2016).

54. Giotopoulou, N. et al. Ras suppressor-1 promotes apoptosis in breast cancer cells by inhibiting PINCH-1 and activating p53upregulated-modulator of apoptosis (PUMA); verification from metastatic breast cancer human samples. Clin Exp Metastasis 32, 255-265, https://doi.org/10.1007/s10585-015-9701-x (2015).

55. Morgia, G. et al. Matrix metalloproteinases as diagnostic (MMP-13) and prognostic (MMP-2, MMP-9) markers of prostate cancer. Urol Res 33, 44-50, https://doi.org/10.1007/s00240-004-0440-8 (2005).

56. Zhang, B. et al. Tumor-derived matrix metalloproteinase-13 (MMP-13) correlates with poor prognoses of invasive breast cancer. BMC Cancer 8, 83, https://doi.org/10.1186/1471-2407-8-83 (2008).

57. Merk, B. C., Owens, J. L., Lopes, M. B., Silva, C. M. \& Hussaini, I. M. STAT6 expression in glioblastoma promotes invasive growth. BMC Cancer 11, 184, https://doi.org/10.1186/1471-2407-11-184 (2011).

58. Lee, S. Y. et al. Characterization of a Novel Anti-Cancer Compound for Astrocytomas. PloS one 9, e108166 (2014).

59. Lian, S. et al. Artesunate attenuates glioma proliferation, migration and invasion by affecting cellular mechanical properties. Oncol Rep 36, 984-990, https://doi.org/10.3892/or.2016.4847 (2016).

60. Xu, W. et al. Cell stiffness is a biomarker of the metastatic potential of ovarian cancer cells. PLoS One 7, e46609, https://doi. org/10.1371/journal.pone.0046609 (2012).

61. Stylianou, A. \& Stylianopoulos, T. Atomic Force Microscopy Probing of Cancer Cells and Tumor Microenvironment Components. BioNanoScience 6, 33-46, https://doi.org/10.1007/s12668-015-0187-4 (2016).

62. Li, Q. S., Lee, G. Y., Ong, C. N. \& Lim, C. T. AFM indentation study of breast cancer cells. Biochemical and biophysical research communications 374, 609-613, https://doi.org/10.1016/j.bbrc.2008.07.078 (2008).

63. Wang, N. et al. miR-135b inhibits tumour metastasis in prostate cancer by targeting STAT6. Oncol Lett 11, 543-550, https://doi. org/10.3892/ol.2015.3970 (2016).

64. Zhang, Y., Tu, Y., Gkretsi, V. \& Wu, C. Migfilin interacts with vasodilator-stimulated phosphoprotein (VASP) and regulates VASP localization to cell-matrix adhesions and migration. The Journal of biological chemistry 281, 12397-12407, https://doi.org/10.1074/ jbc.M512107200 (2006). 


\section{Acknowledgements}

We thank Dr. Panagiotis Papageorgis for providing us with the STAT6 antibody and Christos Fotis for providing the heatmap image summarizing the data from the phosphoproteomic analysis. Also, we thank the members of Prof. C. Deltas' laboratory for technical support related to visualization of protein using the sqChemiDoc XRS+ Imaging System. This work was funded by the European Research Council under the European Union's Seventh Framework Programme (FP7/2007-2013)/ERC Grant Agreement No. 336839-ReEngineeringCancer.

\section{Author Contributions}

M.L. designed the study, performed the experiments, analyzed the data and wrote the manuscript, A.S. performed the AFM experiments and the analysis of the stress fiber formation, reviewed the data and edited the final manuscript, A.M., V.P. and L.A. performed the phosphoprotein's measurement, V.G. and T.S. participated in the study design, data analysis and interpretation, manuscript editing and reviewing and oversaw the project.

\section{Additional Information}

Supplementary information accompanies this paper at https://doi.org/10.1038/s41598-019-44200-8.

Competing Interests: The authors declare no competing interests.

Publisher's note: Springer Nature remains neutral with regard to jurisdictional claims in published maps and institutional affiliations.

(c) (i) Open Access This article is licensed under a Creative Commons Attribution 4.0 International License, which permits use, sharing, adaptation, distribution and reproduction in any medium or format, as long as you give appropriate credit to the original author(s) and the source, provide a link to the Creative Commons license, and indicate if changes were made. The images or other third party material in this article are included in the article's Creative Commons license, unless indicated otherwise in a credit line to the material. If material is not included in the article's Creative Commons license and your intended use is not permitted by statutory regulation or exceeds the permitted use, you will need to obtain permission directly from the copyright holder. To view a copy of this license, visit http://creativecommons.org/licenses/by/4.0/.

(c) The Author(s) 2019 